Revista Educação e Políticas em Debate - v. 8, n. 2, p. 271-287, mai./ago. 2019 -ISSN 2238-8346

\title{
Democratização da educação superior brasileira: um estudo sobre o Sistema de Cotas na Universidade Estadual de Londrina (2004-2017)
}

\author{
Democratization of Brazilian Higher Education: a study of the Quota System at the State \\ University of Londrina (2004-2017)
}

Democratisation de l'Éducation Supérieure Bresilienne: un étude sur le Système de Quotas dans l'Université d'État de Londrina ( 2004-2017)

Luecy Verônica Mendes Garcia David ${ }^{1}$ Universidade Tecnológica Federal do Paraná

Tania da Costa Fernandes ${ }^{2}$ Universidade Estadual de Londrina

Resumo: Este artigo apresenta aos resultados de uma pesquisa realizada no período de 2017 a 2019. O estudo, objetiva-se destacar o aprimoramento nas discussões e trâmites relativos ao sistema de cotas na Universidade Estadual de Londrina. Para isso, emprega-se como método de pesquisa o materialismo histórico dialético e como procedimentos: pesquisa bibliográfica e análise documental. Os resultados demonstram que o sistema de cotas, nesta IES, passou por avaliações que o aperfeiçoaram e ampliaram. Concluímos, desse modo, que esse sistema se trata de uma política de inclusão tanto racial como social, e que requer acompanhamento e avaliação contínuos para que seus objetivos, declarados em legislação, sejam plenamente alcançados e, por fim, que se contribua para a democratização da educação superior.

Palavras-Chave: Políticas Públicas de Cotas. Educação Superior. Gestão. UEL.

Abstract: This article presents the results of a research conducted from 2017 to 2019. In this study, we aim to highlight the improvement in discussions and procedures related to the quota system at the State University of Londrina. In order to achieve this objective, we used dialectical historical materialism as research method, and as methodological procedures bibliographic research and document analysis. The results demonstrate that the quota system in this institution underwent evaluations that improved and expanded it. We conclude that this system is a policy of both racial and social inclusion, and requires continuous monitoring and evaluation in order to fully achieve its stated objectives in legislation, and finally, contribute to the democratization of higher education.

Keywords: Public Policies of Quota. higher Education. Management. UEL.

Résumé: Cet article présente les résultats d'une recherche faite dans la période de 2017 à 2019. Dans cet étude, on ambitionne souligner l'amériolation dans les débats et les formalités relactives au système de quotas de l'Université de l'État de Londrina- UEL. Pour ce faire, on a employé comme méthode d'étude le matérialisme dialectique historique et

\footnotetext{
${ }^{1}$ Mestre em Educação pela Universidade Estadual de Londrina (UEL). Pedagoga da Universidade Tecnológica Federal do Paraná. E-mail: luecy.veronica@gamil.com. Orcid: https://orcid.org/0000-0002-3024-1337 Lattes: http://lattes.cnpq.br/1763393411438166

${ }^{2}$ Doutora em Educação pela Pontifícia Universidade Católica de São Paulo (PUC-SP). Professora Pesquisadora da Universidade Estadual de Londrina (UEL). E-mail: taniafernandes@uel.br. Orcid: https://orcid.org/OOOO0003-0954-0153. Lattes: http://lattes.cnpq.br/5198597852321142.
} 
comme démarches méthodologiques la recherche bibliographique et l'analyse de documentaire. Les résultats montrent que le système de quotas, dans cette Instituition, a passé par évaluations que l'a amélioré et l'a augmenté. On a conclu que ce système est une politique d'inclusion aussi raciale que sociale, et il demande contrôle constant a fin de que ses buts, declarés dans legislation, soient entièrement obtenus et qu'on puisse contribuer pour la démocratisation de l’Éducation Supérieure.

Mots-clés: Politiques Publiques de Qutoas. Éducation Supérieure. Gestion. Uel.

\section{Introdução}

As políticas públicas de Estado têm, de modo significativo, influenciado as políticas educacionais. E, neste contexto, temos presenciado, sobretudo a partir do processo de redemocratização do Estado (na década de 1980), uma ampliação dos movimentos sociais de reivindicação de direitos nas mais diversas dimensões da vida social, econômica, política, cultural e educacional.

Inicialmente, este processo culminou na elaboração da Constituição Federal (CF) de 1988, a partir da qual garante-se, ao menos na forma da Lei, os direitos públicos subjetivos (educação, saúde, moradia e outros), com princípios de igualdade e, particularmente para educação, na Lei de Diretrizes e Bases da Educação Nacional, nº 9.394 de 20 de dezembro de 1996 (LDBEN), que delineia e regulamenta, de modo mais específico que na $\mathrm{CF}$, a organização da educação brasileira.

Trata-se de um conjunto de leis que visa garantir, de algum modo, as conquistas de direitos por parte da classe trabalhadora. No aprofundamento destas conquistas, outras ações e movimentos se intensificaram e, entre eles, nos encontramos com políticas de ação afirmativa que, de modo mais específico, pretende garantir o acesso e a permanência da classe menos favorecida economicamente a um nível de ensino historicamente usufruído pela classe privilegiada: a educação superior.

De acordo com o Plano Nacional de Educação em Direitos Humanos - PNEDH (2007):

[...] as universidades brasileiras, em especial as públicas, em seu papel de instituições sociais irradiadoras de conhecimentos e práticas novas, assumiram o compromisso com a formação crítica, a criação do pensamento autônomo, a descoberta do novo e as mudanças históricas. (BRASIL, 2007, p.37). 
Nesse sentido, a universidade pública e gratuita torna-se um dos espaços privilegiados de produção e transmissão do conhecimento científico, filosófico, artístico e político, historicamente acumulado pela humanidade e, portanto, espaço de formação humana e intelectual de cidadãos e profissionais críticos e politizados, que deveria ser acessado por todos e todas.

O debate a respeito das políticas públicas de ação afirmativa, em particular de cotas, em benefício aos alunos negros e pobres no ensino público universitário, parte do quadro das desigualdades sociais e raciais acumuladas, historicamente, ao longo dos anos em nosso país e contribui para se efetivar esse acesso da classe menos favorecida aos níveis mais elevados de ensino.

Os aspectos legais, constitucionais e educacionais do sistema de cotas são tratados, no Brasil, sob o enfoque do princípio constitucional da igualdade. O direito à educação é garantido na Constituição Federal de 1988 como dever do Estado e as chamadas minorias ${ }^{3}$ devem ter assegurado tal direito por meio deste Estado. Portanto, foi com base no cenário legislativo nacional e internacional, no que diz respeito à Declaração Universal dos Direitos Humanos, que se observou com o passar dos anos a necessidade de equiparação de oportunidades no acesso à educação em nível superior.

O Brasil carrega em sua história um longo período de escravidão, que perdurou por três séculos, no qual os negros foram submetidos a condições desumanas. A esse grupo foi negado todo e qualquer direito. Mesmo após a abolição dos escravos, houve o incentivo à imigração europeia para ocupar postos de trabalho, e essa população continuou relegada, em situação de exclusão e miséria, pois fora deslocada para um “não lugar” (BONILHA e SOLIGO, 2015).

A fim de oportunizar o acesso dessas minorias, surgiram, no início dos anos 2000, as primeiras propostas de ações afirmativas de políticas de reserva de vagas na educação superior, por proposição das próprias comunidades universitárias por meio de deliberações dos conselhos universitários ou por decretos de leis estaduais.

No caso específico da Universidade Estadual de Londrina (UEL), lócus dessa pesquisa, a ação afirmativa de cotas foi normatizada no ano de 2004, e passou por reavaliação nos anos de 2011 e 2017. Posto isto, nesta investigação, indaga-se: quais foram os percalços e quais os avanços da política de cotas implementada pela e na UEL?

Para responder a esta questão, elege-se como objetivo deste estudo destacar como tem sido o aprimoramento nas discussões e nos trâmites relativos ao sistema de cotas na UEL. Para isso, utiliza-se como método de pesquisa o materialismo histórico dialético e como procedimentos metodológicos a pesquisa bibliográfica e a análise documental. O estudo está

\footnotetext{
${ }^{3} \mathrm{O}$ termo minorias empregado neste estudo refere-se à representação das minoritárias de segmentos específicos dentro da sociedade, a exemplo a presença de grupos étnicos (negros e indígenas) na Educação Superior.
} 
vinculado ao Grupo de Pesquisa, CNPQ: Políticas Públicas, Currículo, Gestão e Sociedade e ao Programa de Estudos Complementares em Currículo, Gestão da Educação (PROEGE), ambos desenvolvidos na Universidade Estadual de Londrina.

\section{Sistema de Cotas na UEL: implementação, conquistas e desafios}

Em Londrina, no ano de 2002 - após a Conferência Mundial contra o Racismo, a Discriminação Racial, a Xenofobia e Intolerância Correlatas de Durban -, o movimento negro levou uma demanda reivindicatória, logo no início dos primeiros meses da nova gestão da UEL, e solicitou à reitoria que se iniciassem discussões sobre a implantação de políticas de ações afirmativas na modalidade de cotas para negros.

Segundo Silva,

No caso da Universidade de Londrina, houve a mobilização do movimento negro que estava em sintonia com os acontecimentos nacionais e internacionais de avanço no debate sobre a adoção dessas políticas, principalmente após a Conferência de Durban em 2001. (SILVA, 2012, p.81).

A partir desta reivindicação, iniciou-se um longo período de debates internos que tiveram início ainda no ano de 2002 , e totalizou oito encontros e uma reunião extraordinária com o Conselho de Ensino, Pesquisa e Extensão (CEPE). E, ainda, nos meses que precederam a apreciação da política de cotas, membros da Pró-Reitoria de Graduação estiveram nos Conselhos de Centros para debater a temática com os integrantes desses segmentos universitários. ${ }^{4}$

A Gestão da UEL norteou e amparou-se em documentos institucionais, nacionais e internacionais para propor a implementação da política de cotas aos conselheiros universitários, dentre eles: o disposto do inciso III do art. $3^{\circ}$ da Carta Magna Brasileira “erradicar a pobreza e a marginalização e reduzir as desigualdades sociais e regionais" definido como objetivo fundamental da República Federativa do Brasil (UEL, 2004). Além disso:

A Universidade estabelece como uma de suas finalidades, no inciso IX do artigo $3^{\circ}$ de seu Estatuto, "propiciar condições para a transformação da realidade, visando justiça e equidade social”. Essas prerrogativas permitiram a criação do sistema de reserva de vagas para estudantes oriundos de escola pública e para estudantes que se autodeclararem negros, oriundos de escola pública. Para essa tomada de decisão aconteceram oito debates internos, dezenas de reuniões, uma audiência pública e a realização de eventos como o V Encontro "O Negro na

\footnotetext{
4. Informações retiradas da Ata da reunião $n^{\circ} 416$ do Conselho Universitário da Universidade Estadual de Londrina, realizada dia 23 de julho de 2004. Disponível em: http://www.uel.br/sgocs/portal/pages/arquivos/cu/atas/2004/CU_416_de_23-07-2004.pdf
} 
Universidade: o direito à inclusão", realizado nos dias 13 e 14 de abril de 2004. (PROGRAD/UEL, 2017, grifos nossos)..$^{5}$

Segundo a Reitora Professora Lygia Lumina Puppato (gestão 2002-2006), sua gestão pautou-se por:

\begin{abstract}
[...] colocar esta matéria em discussão, nós nos pautamos na convicção que a Universidade deve cumprir sua responsabilidade, ajudando a construir uma sociedade mais justa, igualitária e fraterna. E com ela buscamos adicionar mais uma ação entre várias outras que já adotamos. Sempre com o objetivo de possibilitar um maior acesso da sociedade à universidade pública, bem como melhorar a sua qualidade e com profundo respeito a todos os cidadãos que através de seus impostos nos sustentam. [...] Toda esta reflexão sobre a possibilidade de cotas nos faz pensar sobre os direitos e cidadania, porque é fundamentalmente disto que tratam as cotas. (UEL, 2004, p. 22).
\end{abstract}

Essa proposição de implementação da política de cotas na UEL foi aprovada pelo Conselho Universitário (CU), dos 43 conselheiros presentes, 31 foram favoráveis, 11 contrários e um se absteve. Podemos observar que, embora a implementação da política de cotas da UEL tenha sido aprovada pela maioria, não existia um consenso entre os conselheiros, ainda que tenha prevalecido o direito democrático.

Em seguida, a UEL passa a publicar as novas regras para a realização do primeiro processo seletivo de concurso de vestibular com a adoção das novas regras dadas pela implementação do novo sistema de cotas. No entanto, o Procurador da República Mário Ferreira Leite, lotado na Justiça Federal de Londrina, comunicou à imprensa local $^{6}$ que impetraria uma ação para tentar suspender o sistema de reserva de cotas da UEL, sob a alegação de inconstitucionalidade e violação ao princípio da igualdade.

No mesmo texto jornalístico, o pró-reitor de graduação da UEL à época, professor Jairo Pacheco, contrapôs o posicionamento do procurador argumentando que:

No mesmo artigo $5^{\circ}$ da Constituição, que garante o princípio da igualdade, o inciso $3^{\circ}$ prevê que o Estado tem que desenvolver ações visando a eliminação ou a diminuição das desigualdades sociais. Temos a percepção de que a política de cotas é uma maneira de compensar isso, afinal se a concorrência acontece em condições extremamente desiguais, não se permite o princípio da igualdade previsto na Constituição se estabeleça de fato (PAPALI, 2004).

Posto esse cenário de incerteza sobre a implementação do sistema de cotas aprovado pela UEL, os movimentos estudantil e negro articularam-se com outros movimentos para contrapor e criticar a decisão do procurador do MPF de Londrina.

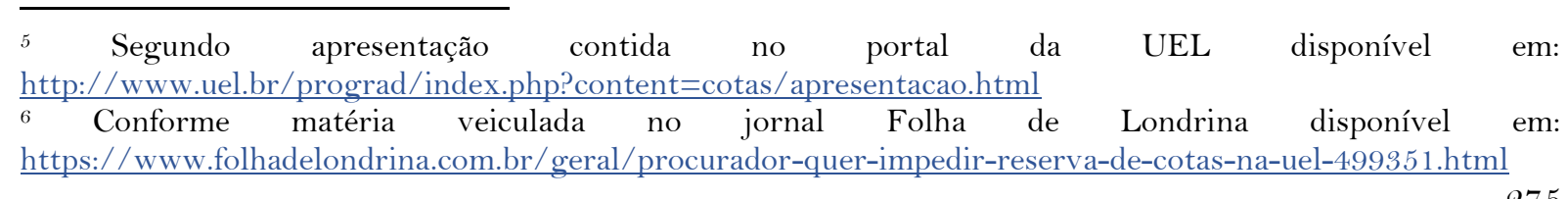


Segundo Araújo ${ }^{7}$ :

A mobilização começou na sede do Diretório Central Estudantil (DCE) e reuniu representantes de 17 entidades. A coleta de assinaturas deve acontecer em diversas regiões da cidade, além da apresentação de uma carta aberta à população sobre o sistema de cotas. [...] Com o abaixo-assinado em mãos, a ideia é levar o documento a conhecimento do Procurador Geral da República, Cláudio Fonteles, em Brasília, para que ele tome conhecimento do interesse da população sobre o sistema. [ ...] Os participantes da mobilização acreditam que a interferência do procurador e a proposta de ação contra o sistema é "inoportuna". "O procurador não possui fundamento histórico para discutir esse assunto. Na reunião que tivemos ele não demonstrou isso claramente. Somos nós, os negros, que também pagamos seu salário para defender os nossos direitos de inclusão", disse a presidente do Conselho Municipal dos Direitos dos Negros, Vilma Santos de Oliveira. Ela lembrou que a proposta do sistema de cotas foi discutida em diversas reuniões e conferências promovidas pela UEL e também pelas entidades envolvidas. [...] "Toda a cidade teve oportunidade de debater" (ARAÚJO, 2004).

A mobilização dos movimentos sociais em Londrina se desdobrou em um abaixoassinado, debates, entrevistas, uma carta aberta sobescrita por 20 entidades e o apoio do Promotor Dr. Paulo César Vieira Tavares.

A ação civil ajuizada sob n ${ }^{\circ}$ 2004.70.01.009347-0 requeria o impedimento da aplicação da Resolução 078/2004, ou seja, que o sistema de cotas não fosse implementado na Universidade Estadual de Londrina, com alegação de inconstitucionalidade. No entanto, a UEL, em sua defesa, questionou a legalidade da Justiça Federal para julgar condutas de uma instituição estadual e aduziu que o sistema de cotas não feria o princípio constitucional da igualdade, e que essa ação pretendia que tal princípio não fosse de fato efetivado.

A alegação da UEL foi considerada pela $1^{\text {a }}$ Vara Federal de Londrina, e considerou ilegítima a ação civil proposta, considerando que se tratava de um órgão da esfera estadual e que não compete ser revisado pela Justiça Federal, extinguindo o processo ${ }^{8}$.

Com o exposto, observa-se o despreparo de membros ligados à justiça em compreender que existem injustiças sociais e que grupos sociais não têm acesso a direitos fundamentais à vida, além de vivenciarem cotidianamente discriminações, ou ainda, que alguns membros desse poder defendem interesses de classes sociais distintas.

\footnotetext{
${ }^{7}$ Segundo matéria publicada em 26/08/2004 pelo Jornal Folha de Londrina encontrada nos arquivos da UEL, cujo página não estava visível.

${ }^{8}$ PROCESSO N. ${ }^{\circ}$ :1.25.005.000625/2004-39 RELATOR: Dra. Aurea Lustosa Pierre INTERESSADO: MPF. ASSUNTO: Análise da constitucionalidade na implantação de cotas universitárias. EMENTA: Constitucional. Infraconstitucional. Direito processual. Ação Civil Pública ajuizada pelo Ministério Público Federal. Implantação de cotas para estudantes da escola pública e para negros. Cotas em Universidade Estadual. Em grau de apelação declinada a competência para a justiça estadual. Definição. Local da ocorrência do dano. CF ART. 205; ART. 5 ${ }^{\circ}$, CAPUT. Ajuizada Ação Civil Pública pelo Ministério Público Federal (ACvP $\mathrm{N}^{\circ}$ 2004.70.01.009347-0). Judicializada a questão, com extinção do feito por ilegitimidade ativa do Ministério Público Federal, não há necessidade de remessa do PA ao Ministério Público Estadual. Pela Homologação do Arquivamento. CONCLUSÃO: Voto aprovado à unanimidade.
} 
Superado este percalço, a gestão da UEL pode implementar o sistema de cotas no vestibular de 2005 como decidido pelo conselho universitário.

É importante esclarecer que algumas mudanças aconteceram na proposta inicial, dentre elas a proporcionalidade expressa no artigo $1^{\circ}$ da Resolução 78/2004 do CU:

Fica estabelecido que até $40 \%$ (quarenta por cento) das vagas de cada curso de graduação, ofertadas em Concurso Vestibular pela Universidade Estadual de Londrina, serão reservadas a estudantes oriundos de Instituições Públicas de Ensino, sendo que até a metade das vagas decorrentes da aplicação deste percentual deverão ser reservadas a candidatos que se autodeclararem negros. (UEL, 2004, p. 1).

E do tempo de vigência contido no artigo $4^{\mathrm{o}}$ “[ [...] deverá vigorar por um período de 7 (sete) anos letivos, contados a partir do ano letivo de 2005 (UEL, 2004).

Segundo Silva, a proposta inicial era:

[...] 40 por cento do total das vagas oferecidas no vestibular seriam destinadas aos candidatos oriundos de escolas públicas, metade das quais seria destinada aos candidatos negros também oriundos de escolas públicas. A proposta inicial previa que a implantação das cotas na UEL teria validade por um período de 10 anos. Havia a preocupação em abranger os estudantes carentes de recursos financeiros e discriminados social e racialmente. (SILVA, 2008, p. 4).

É necessário destacar as alterações da proposta, pois elas tiveram impactos negativos no sistema de cotas durante seus primeiros anos de implementação, embora tenha sido identificado, no acompanhamento após os dados obtidos no primeiro ano de implementação da política, que fora necessário aguardar o tempo de vigência e avaliação da política conforme expresso na resolução.

Decorrido o prazo de vigência da política de cotas, foi apresentado e apreciado nos conselhos o relatório produzido pela Comissão de Acompanhamento e Avaliação do sistema de cotas da UEL. Pode-se encontrar na tabela que segue o número total de matrícula de cada ano por categoria e a percentagem que cada categoria ocupou a cada ano.

Tabela 1 - Total de matriculados - Por Cota de matrícula.

\begin{tabular}{|c|c|c|c|c|c|c|c|}
\hline & TOTAL & \multicolumn{2}{|c|}{ COTA O } & \multicolumn{2}{c|}{ COTA 1 } & \multicolumn{2}{c|}{ COTA 2 } \\
\cline { 3 - 8 } ANO & GERAL & TOTAL & \% & TOTAL & \% & TOTAL & \% \\
\hline 2005 & 3029 & 2017 & 66,59 & 733 & 24,2 & 279 & 9,21 \\
\hline
\end{tabular}


Revista Educação e Políticas em Debate - v. 8, n. 2, p. 271-287, mai./ago. 2019 -ISSN 2238-8346

\begin{tabular}{|c|c|c|c|c|c|c|c|}
\hline 2006 & 3051 & 2010 & 65,88 & 832 & 27,27 & 209 & 6,85 \\
\hline 2007 & 3052 & 2005 & 65,69 & 821 & 26,9 & 226 & 7,4 \\
\hline 2008 & 3021 & 1992 & 65,94 & 819 & 27,11 & 210 & 6,95 \\
\hline 2009 & 2965 & 1962 & 66,17 & 838 & 28,26 & 165 & 5,56 \\
\hline 2010 & 2844 & 1659 & 58,33 & 1003 & 35,27 & 182 & 6,4 \\
\hline TOTAL & 17962 & 11645 & 64,83 & 5046 & 28,09 & 1271 & 7,08 \\
\hline
\end{tabular}

Fonte: PROGRAD / Divisão de Políticas de Graduação, 2010, p.5

Legenda: Cota 0 - cota universal Cota 1 - cota EP Escola Pública Cota 2 - cota PP Preto e Pardo

Observa-se que o percentual de negros (pretos e pardos) já no primeiro ano de implementação, em 2005, corresponde apenas a 9,5\% das matrículas efetivadas, ou seja, menos da metade dos $20 \%$ do que se pretendia com ação afirmativa adotada.

Percebe-se, também, que a ocupação das vagas destinadas aos estudantes negros oriundos da educação básica pública fica ainda mais baixa nos anos seguintes. Analisando o período de 2005 a 2010, esse grupo atingiu a média de 7,08\% apenas das matrículas efetivadas.

O critério de proporcionalidade de (até) 40\% para escola pública e subdivididos para estudantes negros de (até) $20 \%$ foi identificado como o fator gerador do problema. Contudo, era necessário aguardar os resultados das demais entradas de estudantes por meio da regra estabelecida e o relatório de acompanhamento e avaliação do sistema de cotas.

Nota-se que no primeiro ciclo da política a questão da proporcionalidade estabelecida pela Resolução CU 78/2004 fez com que essa política não tivesse o alcance social almejado, ou seja, o ingresso de jovens negros continuou baixo. Visto que para que se atingisse o percentual de até $20 \%$ das vagas ocupadas por negros, no mínimo $20 \%$ dos candidatos inscritos para o curso precisavam ser negros.

Sobre essa questão da proporcionalidade, a representante do Movimento Negro de Londrina, dona Vilma - Yá Makumbi, asseverou que:

O problema da questão da proporcionalidade é o "até" $20 \%$, esse "até" não poderia ter na Resolução, porque ele mascara a situação, porque você fica imaginando que nós temos $20 \%$ de negros e universidade e não temos. As vagas são proporcionais ao número de alunos inscritos no concurso vestibular de $40 \%$ das quais $20 \%$ são para alunos oriundos da escola pública e "até" $20 \%$ das vagas para alunos negros. Porque é assim: eles não conseguem entender que quando a gente luta buscando cotas para negros dentro da universidade, o pessoal não consegue entender que negro é mais pobre no país, que negro não está estudando, não está dentro da escola fundamental, ele não está no ensino médio e ele não está na universidade, ele não está. Nós temos esse n'mero de negros, $2 \%, 1 \%$ de negros que estão. $\mathrm{O}$ que nós vamos fazer? Vamos preparar um material e ir paras escolas incentivar os alunos negros para virem para a universidade se inscrever, porque eles têm 20\% de vagas garantidas. (ANCHIETA, 2008, p.140-141). 
Ressalva-se que esse critério não constava no parecer inicial da gestão da UEL, sendo incorporado após a proposta elaborada pelo Conselho de Centro de Ciências Agrárias (CCA). Este Centro de Estudos, juntamente com o Centro de Ciências da Saúde (CCS), compunham o núcleo mais resistente à política de ação afirmativa que estava sendo pautada. Durante o processo de discussão e construção da política, a gestão da UEL optou por inserir as sugestões que eram viáveis dentro do possível, com o intuito de obter o mais amplo consenso possível para que a política pudesse ser aprovada, uma vez que não existia, na época, um parâmetro que pudesse avaliar os impactos que a proporcionalidade geraria.

Em depoimento, o professor Jairo Pacheco pró-reitor de graduação (gestão 20022006) ponderou que:

Diante de uma forte polarização, às vésperas da apreciação, tínhamos um quadro incerto quanto às possibilidades de vitória. A maneira encontrada para dividir o campo dos contrários foi incorporar a proposta de que o número de vagas destinadas às duas modalidades de cotas (para estudantes de escolas públicas e para estudantes negros da escola pública) seria proporcional ao número de inscritos. (PACHECO, apud SILVA, 2012, p. 82-83).

De acordo ainda com a resolução do CU 078/2004, previu-se que as vagas reservadas para alunos negros de escola pública, quando não ocupadas por esse grupo, passariam para os estudantes de cotas de escola pública e, deste para os que disputavam pela cota universal, ou seja, de ampla concorrência

Observa-se que entre os anos de 2005 a 2010, o percentual de matriculados, cujo único critério era ser estudante da educação básica pública, acabou ficando acima da média prevista pela resolução e ocupou 28,09\% das vagas dos certames de vestibular. Assim como a cota 1, os estudantes da ampla concorrência ou cota 0 também se beneficiaram das vagas não ocupadas pelos estudantes negros da cota 2, neste caso o percentual de matrículas efetivadas ficou em média $64,83 \%$.

Com os números postos fica evidente que as vagas destinadas aos estudantes negros da escola pública foram subutilizadas pelas demais categorias e constata-se que o emprego do critério de proporcionalidade limitou o ingresso dos estudantes negros, público alvo da política de cotas que fora implementada.

A professora Maria Nilza (2008), membro do Núcleo de Estudos Afro-brasileiros (NEAB) da UEL, ressaltou que:

Membros da comunidade negra, professores que participaram dos debates na defesa das mudanças implementadas, demonstraram - se surpresos com o resultado do vestibular de 2005. Somente após uma consulta mais cuidadosa à Resolução do Conselho Universitário que implementou as ações 
afirmativas é que se percebeu que a reserva das vagas estava limitada à proporção de inscritos no vestibular. A resolução 78 do Conselho, quando se refere à percentagem, utiliza a palavra "até", que passou despercebida para muitas pessoas, ou seja, "até" $40 \%$ para estudantes de escola pública e "até" $20 \%$ para os negros. Mesmo após a aprovação das mudanças relacionadas à proposta original não houve preocupação da administração da UEL em informar a comunidade e divulgar a condição de proporcionalidade das cotas e muitos ainda hoje continuam pensando que a UEL destina $40 \%$ das suas vagas às cotas. (SILVA, 2008, p. 6).

Embora o critério de proporcionalidade estivesse expresso na resolução, isso não minimizava a contrariedade que ocorria no ingresso dos estudantes negros e não atingia o que fora almejado pelos movimentos sociais que requereram que a política fosse implantada na universidade, tão pouco o que se propunha o sistema de cotas.

Em relação ao desempenho acadêmico dos estudantes que ingressaram no período de 2005 a 2009, auferido pela média aritmética, temos que:

Tabela 2- Média aritméticas dos estudantes ${ }^{9}$

\begin{tabular}{|c|c|c|c|c|c|}
\hline $\begin{array}{l}\text { Ano ingresso/ } \\
\text { categoria cota }\end{array}$ & 2005 & 2006 & 2007 & 2008 & 2009 \\
\hline Universal $1^{\circ}$ ano & 7,31 & 7,48 & 7,37 & 7,17 & 7,2 \\
\hline Escola Pública $1^{\circ}$ ano & 7,39 & 7,17 & 6,93 & 6,74 & 6,95 \\
\hline Negros $1^{\circ}$ ano & 6,98 & 6,55 & 6,68 & 6,23 & 6,41 \\
\hline Universal $2^{\circ}$ ano & 7,37 & 7,47 & 7,39 & 7,31 & \\
\hline Escola Pública $2^{\circ}$ ano & 7,5 & 7,13 & 7,15 & 6,85 & \\
\hline Negros $2^{\circ}$ ano & 6,98 & 6,57 & 6,51 & 6,18 & \\
\hline Universal $3^{\circ}$ ano & 7,42 & 7,54 & 7,48 & & \\
\hline Escola Pública $3^{\circ}$ ano & 7,53 & 7,18 & 7,21 & & \\
\hline Negros $3^{\circ}$ ano & 6,92 & 6,73 & 6,71 & & \\
\hline Universal $4^{\circ}$ ano & 7,51 & 7,66 & & & \\
\hline Escola Pública $4^{\circ}$ ano & 7,61 & 7,36 & & & \\
\hline Negros $4^{\circ}$ ano & 7,05 & 6,93 & & & \\
\hline Universal $5^{\circ}$ ano & 7,57 & & & & \\
\hline Escola Pública $5^{\circ}$ ano & 7,69 & & & & \\
\hline Negros $5^{\circ}$ ano & 7,2 & & & & \\
\hline
\end{tabular}

Fonte: PROGRAD/UEL

Analisando a média aritmética dos estudantes, pode-se constatar que a diferença do desempenho acadêmico entre estudantes cotistas e não cotistas são mínimas e não chega a ser um ponto.

\footnotetext{
${ }^{9}$ Disponível para acesso em: http://www.uel.br/prograd/index.php? content=cotas/panorama_p3.html
} 
Outros dados importantes, além do desempenho acadêmico, dizem respeito à promoção, retenção e evasão dos estudantes.

Tabela 3 - Panorama de estudantes cotistas e não cotistas formados, retidos e evadidos ${ }^{10}$

\begin{tabular}{|l|c|c|c|c|c|c|c|c|c|}
\hline Ingressantes/ano & \multicolumn{3}{|c|}{ \% Promovidos } & \multicolumn{3}{c|}{ \% Retidos } & \multicolumn{3}{c|}{ \% Evadidos } \\
\hline & $\mathbf{U}$ & $\mathbf{E P}$ & $\mathbf{N}$ & $\mathbf{U}$ & $\mathbf{E P}$ & $\mathbf{N}$ & $\mathbf{U}$ & $\mathbf{E P}$ & $\mathbf{N}$ \\
\hline $2005-1^{\mathbf{0}}$ ano & 82,15 & 84,86 & 80,29 & 9,97 & 11,05 & 15,77 & 7,88 & 4,09 & 3,94 \\
\hline $2005-2^{\mathbf{o}}$ ano & 86,69 & 86,63 & 79,48 & 7,06 & 8,53 & 14,92 & 6,25 & 4,84 & 5,60 \\
\hline $2005-3^{\mathbf{0}}$ ano & 86,17 & 85,50 & 83,47 & 9,70 & 10,17 & 12,20 & 4,13 & 4,33 & 4,33 \\
\hline $2006-1^{\mathbf{0}}$ ano & 85,12 & 81,97 & 75,12 & 8,11 & 14,9 & 22,49 & 6,77 & 3,13 & 2,39 \\
\hline $2006-2^{\mathbf{0}}$ ano & 84,67 & 79,9 & 75 & 9,29 & 14,52 & 20,59 & 6,04 & 5,58 & 4,41 \\
\hline $2006-3^{\mathbf{0}}$ ano & 83,93 & 79,4 & 71,28 & 10,22 & 14,44 & 18,46 & 5,85 & 6,17 & 10,26 \\
\hline $2007-1^{\mathbf{0}}$ ano & 80,30 & 77,34 & 74,34 & 8,18 & 15,71 & 20,80 & 11,52 & 6,94 & 4,86 \\
\hline $2007-2^{\mathbf{o}}$ ano & 83,48 & 79,19 & 73,02 & 9,3 & 11,52 & 21,86 & 7,22 & 9,29 & 5,12 \\
\hline $2008-1^{\mathbf{0}}$ ano & 77,01 & 74,24 & 66,19 & 12,20 & 18,19 & 25,71 & 10,79 & 7,57 & 8,10 \\
\hline
\end{tabular}

Fonte: PROGRAD/UEL

Legenda: $\mathrm{U}=$ universal; $\mathrm{EP}=$ escola pública, $\mathrm{N}=$ negros

Observa-se que o percentual de estudantes retidos dos estudantes cotistas independente de subdivisão é maior que o percentual dos estudantes que entraram pela cota universal, principalmente nos anos iniciais. No entanto, nota-se uma inversão quando se trata de evasão, o público que mais se evade é maior na cota universal do que nas demais cotas de estudantes oriundos da escola pública.

Com os dados apontados pela Pró-reitora de Graduação (PROGRAD) da UEL e relatório da Comissão de Acompanhamento e Avaliação do sistema de cotas da instituição, os Centros de Estudos puderam analisar e fazer proposições que foram debatidas no Conselho Universitário. De acordo com a compilação das propostas apresentadas, os segmentos universitários eram unanimes em manter a porcentagem de 40\% de reserva de vaga, no entanto, divergiam em relação à distribuição/público alvo, proporcionalidade e tempo de duração da política de cotas da UEL, conforme a sistematização das propostas apresentadas aos conselheiros do CU, conforme a Ata da reunião realizada no dia 26 de agosto de 2011 :

1.Porcentagem de vagas destinadas: I. Proposta única de 40\%. 2.Característica de distribuição: I. $20 \%$ candidatos que se autodeclararem negros e $20 \%$ candidatos das escolas públicas; II. $40 \%$ candidatos advindos de escolas públicas; III. $40 \%$ candidatos comprovadamente de baixa renda (cotas sociais).3. Proporcionalidade: I. Com proporcionalidade; II. Sem proporcionalidade. 4. Tempo: I. Reavaliação em 5 anos; II. Extinção em 5 anos; III. Redução gradativa de $5 \%$ ao ano até extinção do sistema de cotas

${ }^{10}$ Disponível para acesso em: http://www.uel.br/prograd/index.php? content=cotas/panorama_p3.html 
em 8 anos; IV. Reavaliação em 7 anos; V. Reavaliação em 5 anos, contagem iniciada a partir de 2013 (UEL, 2011, p. 299, grifos nossos).

Em relação às propostas de percentagem de distribuição das vagas, apenas uma contemplava o recorte étnico-racial contra duas propostas de cunho estritamente social. Sobre a proporcionalidade, item que já vinha sido discutido pois limitava o acesso dos negros as vagas, ainda aparecia nas propostas. Na determinação da vigência da política, o que chama a atenção entres as cinco apresentadas, é que duas propõem a extinção do sistema de cotas depois de um determinado tempo. Decorrido sete anos da implementação do sistema de cotas da UEL, percebe-se por estas proposições, que ainda não há um entendimento ajustado entre os segmentos universitários. Também podemos inferir que existe uma disputa no campo ideológico. No entanto, a maioria dos conselheiros deliberam pelo fim da proporcionalidade e manutenção da percentagem de 40\% das vagas para estudantes da escola pública, sendo deste $20 \%$ para negros, pela reavaliação em cinco anos e não extinção do sistema de cotas.

De acordo com o exposto no relatório da Comissão de Acompanhamento e Avaliação da política de cotas que compreende os anos de 2011 a 2016, o sistema foi avaliado após cinco anos do seu segundo ciclo, sendo revisto e aprimorado. Contudo, deste ciclo, pode-se avaliar apenas os anos de 2013 a 2016, visto que o primeiro vestibular após as adequações do primeiro ciclo se deu no ano de 2013. Esse intervalo de tempo de apenas quatro anos letivos, restringe a obtenção de dados de concluintes de cursos, pois até o final dos trabalhos da comissão, não havia turmas concluintes que ingressaram pelas regras dadas pela resolução 015/2012 ${ }^{11}$.

Neste interstício de tempo, o Supremo Tribunal Federal aprovou em abril de 2012 a constitucionalidade das ações afirmativas, após ação impetrada pelo partido Democratas (DEM) que questionava a legalidade das cotas após a Universidade de Brasília (UNB) implementar sua política de cotas em 2004. Logo após, o governo federal sancionou a lei 12.711 que instituiu a reserva de vagas em todas as instituições federais de educação superior. Essa conquista, no âmbito federal, corroborou e ratificou o sistema de cotas da UEL.

No ano de 2017, o sistema de cotas da UEL passa pelo processo de reavaliação, decorrido o período de quatro anos previstos pelo artigo 11 da resolução 015/2012 do CU que assim determinou "o percentual de vagas [...] deverá vigorar por um período de cinco anos letivos, contando a partir do ano letivo de 2013 (UEL, 2012) ". Durante o mês de janeiro foram realizados quatro debates com a temática "Ações Afirmativas e Cotas na UEL: avaliação e perspectivas", nos dias 18 e 19 de janeiro de 2017.Os debates aconteceram no anfiteatro do Centro de Letras e Ciências Humanas - CLCH e no Centro de Ciências da 
Saúde - CCS no anfiteatro, localizado no Hospital Universitário - HU. Para esses debates, a UEL convidou o Prof. Dr. José Jorge de Carvalho ${ }^{12}$ da Universidade de Brasília, que foi um dos idealizadores da proposta de cotas da UNB, primeira universidade federal a adotar cotas raciais nos processos seletivos de vestibular.

Nos dias 25 e 26 do mesmo mês e ano, os debates foram conduzidos pelo Prof. Dr. Marcelo Tragtenberg ${ }^{13}$, da Universidade Federal da Santa Catarina - UFSC, e pelo Prof. Dr. André Lázaro ${ }^{14}$, da UERJ e Faculdade Latino-Americana de Ciências Sociais, Sede Acadêmica Brasil - FLACSO estes foram realizados no auditório da OAB e no anfiteatro do Centro de Ciências Biológicas - CCB. Esses debates foram importantes para a reavaliação do sistema de cotas da UEL, uma vez que dessas discussões suscitou a ampliação do tempo de vigência da política, bem como a inclusão de cotas para negros de qualquer percurso escolar.

No dia 17 de fevereiro de 2017, o Conselho Universitário da UEL reuniu-se para apreciar o Relatório da Comissão Permanente de Acompanhamento e Avaliação da Política de Cotas na instituição e Minuta de Resolução, que estabelece a reserva de vagas no Processo Seletivo Vestibular para candidatos oriundos de instituições públicas brasileiras de ensino e para aqueles que se autodeclararem negros.

Em votação unânime, os conselheiros aprovaram a participação de entidades, movimentos sociais e instituições relacionadas com as discussões sobre cotas na universidade com o pronunciamento de representantes, dentre eles, Dr. Paulo Tavares (Promotor de Justiça do Ministério Público do Paraná-Londrina), Dr. Sebastião Ramos Neto (Diretor da Escola Superior da Polícia Civil), Professora Lucia Cortez (Chefe do Núcleo Regional de Educação de Londrina) e Dr. Oscar Nascimento (Advogado negro mais antigo de Londrina).

O professor Adriano Farinasso, presidente da Comissão Permanente de Acompanhamento e Avaliação da Política de Cotas na UEL, relatou que:

A UEL vem, nos últimos anos, apresentando um crescente e positivo resultado em relação às avaliações da instituição, pois houve um significativo aumento do ingresso de estudantes negros oriundos da escola pública no decorrer dos anos. A UEL foi uma das pioneiras que instituiu o sistema de cotas, que foi a partir do vestibular de 2005 e também tem um histórico de construção da política de ações afirmativas. (UEL, 2017, p. 227).

\footnotetext{
12 Antropólogo, professor titular da UnB, tem atuado na criação de políticas afirmativas (cotas raciais para estudantes negros e indígenas) também atua como diretor do INCT - Instituto Nacional de Ciência e Tecnologia e Inclusão no Ensino Superior e na Pesquisa, Ministério de Ciência e Tecnologia.

${ }^{13}$ Físico, professor associado da UFSC, ocupa o cargo de diretor da Secretaria de Ações Afirmativas e Diversidades.

${ }^{14}$ Professor adjunto da UERJ e coordenador acadêmico da FLACSO onde atua como pesquisador e ocupa também a coordenação do Programa Políticas de Educação Superior.
} 
De acordo com o professor Adriano, a comissão considerou as recomendações do Ministério Público e do Grupo de Trabalho de Combate ao Racismo pela manutenção do sistema de cotas e que a revisão seja feita após 15 ou 20 anos. Dessa forma a comissão propôs:

[...] manutenção do sistema de reserva de vagas no formato de cotas alterando a proporcionalidade para $20 \%$ do total das vagas para estudantes oriundos de instituições de ensino público, $15 \%$ do total das vagas para estudantes negros de instituições de ensino público e $5 \%$ do total das vagas para negros de forma irrestrita, independente do percurso de formação, totalizando $40 \%$ das vagas reservadas para Ações Afirmativas; Que o sistema de vagas vigore por vinte anos letivos; Criar novas políticas de permanência e fortalecer as existentes também dentro da questão pedagógica e psicológica.(UEL, 2017 p. 228).

No entanto, a presidente da sessão do CU compartilhou com os presentes que no dia anterior o respectivo processo foi apreciado pelo Conselho de Ensino Pesquisa e Extensão (CEPE), que, após análise do Relatório apresentado pela Comissão Permanente de Acompanhamento e Avaliação do Sistema de Cotas da UEL, recomendou ao Conselho Universitário:

1) Manter o sistema de cotas na UEL;

2) Alterar a política do atual sistema de cotas sendo: 40\% das vagas reservadas para estudantes de escola pública, sendo que metade destas, para negros oriundos de escola pública e, mais $5 \%$ das vagas reservadas para negros de qualquer percurso escolar, totalizando $45 \%$ de vagas para ações afirmativas (proposta da Câmara de Graduação) […].(UEL, 2017, p. 228).

Dando continuidade, a palavra foi dada ao Dr. Paulo Tavares que, por sua vez, defendeu a manutenção do sistema de cotas por um período de 15 a 20 anos e sua importância como política e, ainda, que

[...] o Ministério Público está aqui hoje, por compromisso, dever e defensor da sociedade mais livre e mais justa, defender a ordem jurídica e democrática, decidir que País que queremos? Nunca num curso de Direito tinha negros e o sistema de cotas proporciona isso. Sou favorável a política de permanência e ao sistema de cotas para uma sociedade livre mais justa. (UEL, 2017, p. 228).

Encerrados os pronunciamentos, iniciou-se o debate entre os presentes, após longa discussão, a reitora à época, Professora Berenice Quinzani Jordão (gestão 2014-2018) colocou em votação a continuidade ou extinção do sistema de cotas da UEL e os conselheiros votaram por unanimidade pela manutenção da política de cotas da UEL.

Assim sendo, o CU aprovou:

1) Manter o Sistema de Cotas na Universidade Estadual de Londrina; 
2) Alterar o sistema de reserva de vagas no Processo Seletivo Vestibular para candidatos oriundos de instituições públicas brasileiras de ensino e para aqueles que se autodeclararem negros sendo: " $40 \%$ das vagas reservadas para estudantes de escola pública, sendo que metade destas para negros oriundos de escola pública e, mais $5 \%$ das vagas reservadas para negros de qualquer percurso escolar, totalizando $45 \%$ de vagas para Ações Afirmativas";

3) A inclusão de 1(um) representante da Comissão Própria de Avaliação (CPA) na Comissão Permanente de Acompanhamento e Avaliação da Política de Cotas na UEL;

4) A inclusão de 1(um) representante discente, indicação do DCE, na Comissão Permanente de Acompanhamento e Avaliação da Política de Cotas na UEL e

5) A permanência do Sistema de Cotas da UEL a vigorar por 20(vinte) anos letivos sendo revisado a partir do $10^{\circ}$ (décimo) ano de implantação. (UEL, 2017, p. 230-231).

É possível perceber que após uma década da implementação do sistema de cotas na UEL, mesmo havendo conflitos ideológicos entre os membros do CU, as avaliações e acompanhamento do sistema de cotas implantado no ano de 2004 na instituição, passaram a compreender a importância desta política destinada a estudantes de escola pública, dentre eles, os negros. Os ciclos de debates promovidos nos centros de estudos contribuíram para que os dados fossem apresentados e discutidos, e todas as dúvidas e incertezas em relação ao sistema de cotas puderam ser gradualmente esclarecidas e pontuadas.

\section{Considerações Finais}

Verificou-se, com a pesquisa, que a política de cotas, no caso específico da UEL, partiu da reivindicação do movimento negro londrinense fazendo com que se iniciassem os debates relativos ao tema e a Pró-reitora de Graduação à época propusesse uma discussão com a comunidade interna.

No que toca à gestão do sistema de cotas, constatou-se que desde sua implementação foi previsto nas resoluções, a partir da resolução do CU 78/2004, que a política de cotas seria acompanhada e avaliada por uma comissão própria nomeada pelo Conselho de Ensino, Pesquisa e Extensão, com a finalidade de analisar o panorama geral dos ingressantes, desde a inscrição do vestibular, como ingresso, evolução nos estudantes em seus respectivos cursos, bem como índices de evasão e conclusão a fim de estabelecer comparativos entre os estudantes das três categorias: cotistas de escola pública, cotistas negros de escola pública e não cotistas.

Assim, essa comissão foi responsável por analisar as possíveis falhas do sistema de cotas, a exemplo da questão da proporcionalidade que constava na primeira resolução de criação da política de cotas da UEL, que condicionava a reservada de vagas de acordo com o 
número de inscritos no vestibular, e não a oferta de vagas dos cursos. Na avaliação da segunda fase (2013 a 2016), a comissão verificou que o período de avaliação deveria ser maior para que pudesse ter dados dos alunos formandos, visto que em quatro anos nem todos os ingressantes teriam concluídos seus cursos, em especial os estudantes dos cursos com duração de cinco anos.

Quando dos períodos de deliberações dos processos decisórios no Conselho Universitário da UEL em relação ao sistema de cotas, desde sua implementação e suas avaliações, evidencia-se o conflito das representações (ideias) sobre a temática, bem como as divergências inerentes ao campo político-ideológico de seus membros. No entanto, as discussões no CU oportunizaram o debate das ideias que, ao final, são postas em votação para obter-se a decisão colegiada, pautando-se pela democracia.

\section{REFERÊNCIAS}

ARAÚJO, Fernando. Entidades saem em defesa das cotas na UEL. Jornal de Londrina. Londrina, 25 ago. 2004.

ANCHIETA, Karen de Abreu. História da implementação do sistema de cotas para negros na Universidade Estadual de Londrina (2000-2005). 2008, 148 p. Dissertação (Mestrado em Educação) - Universidade Estadual de Londrina, Londrina, 2008.

BRASIL. Comitê Nacional de Educação em Direitos Humanos. Plano Nacional de Educação em Direitos Humanos. Brasília: SEDH, MJ, UNESCO, 2007.

PAPALI, Chiara. Procurador quer impedir reserva de cotas na UEL. Folha de Londrina, Londrina, 04 ago. 2004.

Bonilha, Tamyris Proença; Soligo, Ângela Fátima. (2015). O não-lugar do sujeito negro na educação brasileira. Revista Iberoamericana De Educación, 68(2), 31-48. DOI: https://doi.org/10.35362/rie682183. Disponível em

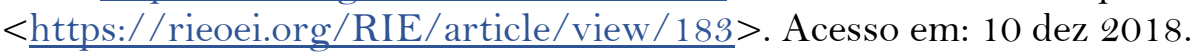

SILVA, Maria Nilza da. O negro em Londrina: da presença pioneira negada à fragilidade das ações afirmativas na UEL. Revista Espaço Acadêmico, v. 82, p. 1-10, 2008. Disponível em < http://livrozilla.com/doc/386417/o-negro-em-londrina--da-presen\%C3\%A 7a-pioneiranegada-\%C3\%A0-fragil...>. Acesso: 18 out. 2018.

SILVA, Maria Nilza. Uma Década das Ações Afirmativas na UEL (2004-2014). IN SANTOS, Jocélio Teles dos. Cotas nas universidades: análises dos processos de decisão. Salvador: CEAO, v. 202, 2012. https://doi.org/10.21669/tomo.v0i0.3190

UNIVERSIDADE ESTADUAL DE LONDRINA (UEL). Conselho Universitário. Ata da reunião realizada no dia 23 de julho de 2004. Livro $\mathrm{n}^{\circ}$ 12, p. 21-34 Disponível em: <http://www.uel.br/sgocs/portal/pages/arquivos/cu/atas/2004/CU_416_de_23-07-

2004.pdf>. Acesso em: 04 set. 2018. 
UNIVERSIDADE ESTADUAL DE LONDRINA (UEL). Conselho Universitário. Ata da reunião realizada no dia 29 de julho de 2011. Livro $n^{\circ}$ 16, p. 283-293 Disponível em: $<\underline{\mathrm{http}}$ //www.uel.br/sgocs/portal/pages/arquivos/cu/atas/2011/CU 545 de 29-072011.pdf>. Acesso em: 04 set. 2018.

UNIVERSIDADE ESTADUAL DE LONDRINA (UEL). Conselho Universitário. Ata da reunião realizada no dia 26 de agosto de 2011. Livro $\mathrm{n}^{\circ}$ 16, p. 298-315 Disponível em: $<$ http://www.uel.br/sgocs/portal/pages/arquivos/cu/atas/2011/CU_545_de_29-072011.pdf>. Acesso em: 04 set. 2018.

UNIVERSIDADE ESTADUAL DE LONDRINA (UEL). Conselho Universitário. Ata da reunião realizada no dia 17 de fevereiro de 2017. Livro $\mathrm{n}^{\circ}$ 19, p. 226-234 Disponível em:

<http://www.uel.br/sgocs/portal/pages/arquivos/cu/atas/2017/CU 0663 de 17-022017.pdf>. Acesso em: 04 set. 2018.

UNIVERSIDADE ESTADUAL DE LONDRINA (UEL). Politica de Cotas da UEL. Disponível

$<$ http://www.uel.br/prograd/index.php?content=cotas/apresentacao.html >.Acesso em: 04 jul. 2017.

UNIVERSIDADE ESTADUAL DE LONDRINA (UEL). Resolução CU 78 de 2004. Estabelece a reserva de vagas no Concurso Vestibular para candidatos oriundos de Instituições Públicas de Ensino e para aqueles que se autodeclararem negros. Disponível em: $<$ http://www.uel.br/prograd/docs_prograd/resolucoes/resolucao_78_04.pdf $>$.Acesso em: 04 jul. 2017. 